Original

\title{
Prevalence of Cryptosporidium, Cyclospora cayetanensis and Isospora belli infection among diarrheal patients in South India
}

\author{
Kammili Nagamani ${ }^{*}$, Pavuluri Pandu Ranga $\mathrm{Rao}^{2}$, Gyaneshwari Mathur ${ }^{1 \mathrm{a}}$, \\ Gudiseva Thandava Phani Krishna ${ }^{3}$, Anuradha Pattepu Rajalingam ${ }^{1}$ and Nirmal Kumar Saxena ${ }^{1}$ \\ Received 18 October, 2007 Accepted 30 June, 2008 Published 8 August, 2008
}

\begin{abstract}
The emerging protozoan parasites Cryptosporidium, Cyclospora cayetanensis and Isospora belli have altered the etiological spectrum of diarrhea. The progressive decline in CD4 cell count in AIDS patients and lack of active immunity in the face of exposure to contaminated food and water in young children make these groups of persons particularly susceptible to protracted and severe diarrhea caused by the above parasites. Cryptosporidiosis is caused by human as well as several zoonotic species. The present study was undertaken to examine the prevalence of Cryptosporidium species, C. cayetanensis and I .belli among these two susceptible populations in comparison with adult immunocompetent individuals with diarrhea and to identify the Cryptosporidium species prevalent in these populations. A total of 447 children under the age of 5 years, 175 HIV-seropositive adults and 200 HIV seronegative adults with diarrhea attending tertiary care hospitals located in the twin cities of Secunderabad and Hyderabad in South India were included in the study. Single fecal samples were collected. Wet mounts and modified Ziehl Neelsen stained smears made from concentrated fecal specimens were screened microscopically for oocysts of Cryptosporidium, Cyclospora cayetanensis and Isospora belli. DNA extracted from fecal samples positive for Cryptosporidium was subjected to PCR RFLP for species identification. Cryptosporidium was detected in all the three groups, i.e. children (8.7\%), HIV-seropositive adults $(6.85 \%)$, and HIV-seronegative adults (1\%). Isospora and Cyclospora were detected only among HIV- seropositive persons at a frequency of $16 \%$ and $1 \%$ respectively. C. hominis (71.7\%) and C. parvum (18.9\%) were the only 2 species of Cryptosporidium detected.
\end{abstract}

Keywords: Cryptosporidium, Cyclospora, Isospora, diarrhea, children, HIV

\section{INTRODUCTION}

The emerging intestinal protozoan parasites Cryptosporidium, Cyclospora and Isospora have altered the etiologic spectrum of diarrhea. Acquired immunodeficiency syndrome (AIDS) has played a key role in the recognition and understanding of these parasites [1]. Initially recognized as opportunistic pathogens in immunocompromised persons, these parasites were shown to be associated with sporadic, epidemic and endemic disease in immunocompetent persons worldwide [2, 3, 4]. The new enteric protozoa cause profuse diarrhea, decreasing the quality of life and increasing the risk of death among immunocompromised patients. Their role in pediatric diarrhea, leading to morbidity and malnutrition in developing countries, has been docu- mented [5, 6, 7]. The progressive decline in CD4 cell count which begins in the gastrointestinal mucosa in AIDS patients and the lack of active immunity in the face of exposure to contaminated water and food in young children make these two groups of persons particularly susceptible to protracted and severe diarrhea caused by the above parasites. Isosporiasis and cyclosporiasis are caused exclusively by the human species of the coccidian parasites, I. belli and C. cayetanensis respectively which spread from person to person [4, 8]. Several species of Cryptosporidium cause human infection. Besides the human species $C$. hominis, several animal species have been reported to cause infection in HIV-infected persons as well as in children $[9,10,11,12$, 13 ].Genus Cryptosporidium is a phenotypically and genotypically heterogeneous assemblage of largely morphologi-

\footnotetext{
'Dept. of Microbiology, Gandhi Medical College, Secunderabad, Andhra Pradesh, India.

${ }^{\text {la }}$ Presently working at Shadan Institute of Medical Sciences, R. R district, Andhra Pradesh, India.

${ }^{2}$ Dept. of Biotechnology, College of Veterinary Sciences, Hyderabad, Andhra Pradesh, India.

${ }_{3}^{3}$ Internee Gandhi Hospital, Secunderabad, Andhra Pradesh, India

*Corresponding author:

E mail: nagamaniy2k03@rediffmail.com

phone: +919966533327

Fax: 040 - 27502742
} 
cally identical species and genotypes. Fourteen species and twenty one $C$.parvum genotypes are currently recognized. Furthermore, the taxonomy of this genus is undergoing rapid changes. Long thought to be closely related to coccidia, it is the subject of increasing attention, and emerging information on its unique morphological, biological and molecular characteristics support the need for reconsideration of its taxonomy. [14].

In India, diarrhea is a major public health problem among children under the age of 5 years. In addition there is a large population of HIV-infected persons among whom diarrhea is a common complication, inducing weight loss and cachexia. Although meager at present, knowledge of the etiology and information on the prevalence of the new intestinal protozoa is a prerequisite for the institution of control measures and specific treatment. Cryptosporidium has been reported in pediatric and HIV-seropositive patients from different parts of the country based on fecal microscopy $[15,16,17,18,19,20,21]$, but only a few studies have genotyped the parasite $[10,11,22]$. Moreover, there are no prospective studies on the prevalence of Cyclospora and Isospora among Indian children eventhough they have been reported to cause diarrhea among children in developing countries $[1,4,6,7]$. The present study was undertaken to determine the prevalence of Cryptosporidium, $C y$ clospora cayetanensis and Isospora belli infection among the two susceptible populations of young children and HIVinfected patients in comparison to HIV-seronegative immunocompetent adults with diarrhea in South India and to identify the Cryptosporidium species prevalent in these populations.

\section{MATERIALS AND METHODS}

The present study was approved by the Institutional Ethical Committee of Gandhi Medical College, Secunderabad. A total of 447 children under 5 years of age, 175 HIVseropositive adults with diarrhea and $200 \mathrm{HIV}$-seronegative adults with diarrhea admitted to tertiary care hospitals in the twin cities of Hyderabad and Secunderabad during the period from April 2004 to March 2006 were included in the study. The criteria for inclusion in the study included diarrhea and other gastrointestinal symptoms. Using WHO guidelines, a case of diarrhea was defined as the passing of $\geq 3$ liquid stools in a twenty-four hour period. Distinct episodes were separated by at least 2 days free of diarrhea. Persons who had received antibiotic therapy in the preceding two weeks were excluded from the study. HIV testing was done according to the National AIDS Control Organization, India guidelines after obtaining informed consent. Clinical and demographic data was recorded with regard to age, sex, and socio-economic status, duration of illness and source of water.

Single fecal samples were collected from all the patients. Sample processing and conventional diagnosis was done in the Department of Microbiology, Gandhi Medical College. Molecular work was done in the Department of Biotechnology, College of Veterinary Sciences, Hyderabad. Fecal samples were concentrated by the formalin ethyl acetate sedimentation method. Microscopic screening of wet mounts and modified Ziehl Neelsen stained smears was done for oocysts of Cryptosporidium, Cyclospora and Isospora [23]. For genotyping of Cryptosporidium, DNA was extracted from all the positive samples using QIA amp DNA stool kit and subjected to two step nested PCR which amplified 18s rRNA sequence, unique to all species of Cryptosporidium, followed by RFLP analysis using the primers and protocol described earlier [24]. A PCR product of $1.3 \mathrm{kbp}$ was amplified using total DNA isolated from the stools. Each PCR reaction $(100 \mu$ l volume) contained $10 \mu \mathrm{l}$ of 10X Taq Buffer, dNTP (10mM each), 20 pmoles each primers (Forward 5'TTCTAGAGCTAATACATGCG-3 and reverse 5' CCATTTCCTTCGAAACAGGA - 3'), 10 $\mu$ l of $15 \mathrm{mM} \mathrm{MgCl}_{2}, 0.01 \mathrm{mg}$ of BSA, $2.5 \mathrm{U}$ of Taq polymerase and $2 \mu 1$ of DNA sample/template. A total of 35 cycles each consisting of $94^{\circ} \mathrm{C}$ for 45 seconds, $55^{\circ} \mathrm{C}$ for 45 seconds and $72^{\circ} \mathrm{C}$ for 60 seconds were performed with initial denaturation at $94^{\circ} \mathrm{C}$ for 3 minutes and a final extension step at $72{ }^{\circ} \mathrm{C}$ for 7 minutes. A nested PCR with expected product size of 836 - 849 bp (depending on species) was done by using $2 \mu \mathrm{l}$ of a primary PCR product and nested primers (Forward 5'GGAAGGGTTGTATTTATTAGATAAAG-3' and reverse 5' -TCATAAGGTGCTGAAGGAGTA -3) . The PCR mixture and cycling conditions were identical to the conditions used for primary PCR except that the annealing temperature was $58^{\circ} \mathrm{C}$.

RFLP: For restriction fragment length analysis for genotyping , $20 \mu \mathrm{l}$ of secondary PCR product was digested in a $50 \mu 1$ reaction mixture containing 10 units of Sspl or Vsp1 (Fermentas, Life Science) and $5 \mu 1$ of appropriate restriction buffer at $37^{\circ} \mathrm{C}$ overnight. The digested products were analyzed on a $2 \%$ agarose gel containing ethidium bromide at a concentration of $0.5 \mu \mathrm{g} / \mathrm{ml}$.

Statistical analysis of data was done using Chi Square test. A P value less than 0.05 was considered significant.

\section{RESULTS}

The emerging protozoan parasites were detected in 42 (24\%) HIV-seropositive, $39(8.7 \%)$ children and 2 (1\%) HIV-seronegative adults with diarrhea. The high prevalence 
Table 1: Coccidian parasites detected

\begin{tabular}{lccc}
\hline \multicolumn{1}{c}{ Coccidian parasite } & $\begin{array}{c}\text { HIV seropositive } \\
\text { adults }(\mathrm{n}=175)\end{array}$ & $\begin{array}{c}\text { Children }<5 \text { yrs } \\
(\mathrm{n}=447)\end{array}$ & $\begin{array}{c}\text { HIV seronegative } \\
\text { adults }(\mathrm{n}=200)\end{array}$ \\
\hline Cryptosporidium & $12(6.85 \%)$ & $39(8.7 \%)$ & $2(1 \%)$ \\
Cyclospora & $2(1.14 \%)$ & 0 & 0 \\
Isospora & $28(16 \%)$ & 0 & 0 \\
\hline
\end{tabular}

Table 2: Cryptosporidium species distribution:

\begin{tabular}{|c|c|c|c|c|}
\hline Category & C.hominis & C.parvum & Mixed & Other spp \\
\hline Children $(n=39)$ & $27(69.2 \%)$ & $7(17.9 \%)$ & $5(12.8 \%)$ & 0 \\
\hline $\begin{array}{l}\text { HIV seropositive } \\
\text { adults }(n=12)\end{array}$ & $9(75 \%)$ & $3(25 \%)$ & 0 & 0 \\
\hline $\begin{array}{l}\text { HIV seronegative } \\
\text { adults }(n=2)\end{array}$ & 2 & 0 & 0 & 0 \\
\hline
\end{tabular}

of the parasites among HIV-infected persons in comparison to immunocompetent children and adults was statistically significant $(\mathrm{P}<0.05)$. Cryptosporidium was found in all of the three groups of subjects studied (Table-1). The prevalence of Cryptosporidium infection in children was higher than that in HIV-seropositive adults but the difference was not statistically significant $(\mathrm{P}>0.05)$. C. cayetanensis and I. belli were detected only in the HIV-infected adults.

The mean duration of Cryptosporidial diarrhea in children was 4 days, whereas in HIV-infected persons it was 10 days. In comparison prolonged diarrhea (mean duration 21 days) was associated with isosporiasis and the difference was statistically significant (difference between means greater than $2 \mathrm{SE}$ of difference between the means). The median age of pediatric cases was 18 months while that of the adult population was 35 years. All of the subjects included in the study were from urban or semi-urban communities. They were of low socio-economic status, but piped municipal water was the only source of water.

A total of 53 samples were positive for Cryptosporidium. In the Nested PCR-RFLP (Fig-1), $C$. parvum and $C$. hominis generated 3 visible bands at 447, 270 and $101 \mathrm{bp}$ on Ssp1 digestion. The two species were differentiated by the Vsp1 digestion pattern. $C$. parvum produced 2 visible bands at 627 and 115 bp. $C$. hominis generated 2 visible bands at 556 and $115 \mathrm{bp}$ due to the presence of one additional Vsp1 restriction site. The species of Cryptosporidium detected were C. hominis $38(71.7 \%)$ and $C$. parvum 10 $(18.9 \%)$. Mixed infection with the above two species was found in 5 cases $(9.4 \%)$. The distribution of Cryptosporidium species among the different groups is shown in Table 2.

\section{DISCUSSION}

Diarrhea is a common complication among HIV-
Fig: 1

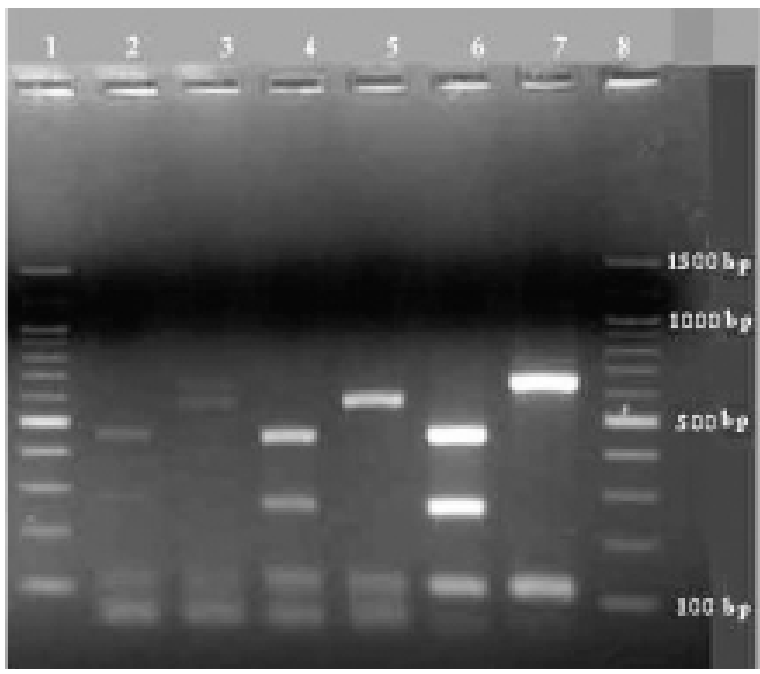

Figure 1: Legend.

Genotyping of Cryptosporidium: PCR - RFLP

Lane.1, 8 - 100bpmarker

Lane.2, 3 - C. parvum \& C. hominis (mixed)

Lane.4, 5- C.hominis

Lane.6, 7-C.parvum

infected persons and young children living in developing countries and it induces weight loss and cachexia. Intestinal coccidiosis causing diarrhea was infrequently reported before the emergence of HIV epidemic. The first from India, this study was conducted to examine the prevalence of the new apicomplexan parasites among two susceptible populations and thus to shed light on the occurrence of these parasites in the environment. The emerging parasites were detected in $42(24 \%)$ HIV-seropositive adults, 39 (8.7\%) chil- 
dren and $2(1 \%)$ HIV-seronegative adults with diarrhea.

In our study $8.7 \%$ of children with diarrhea were infected with Cryptosporidium, which is less than the previous report of $13.1 \%$ from South India [15]. However, much lower prevalence rates have been reported among children with diarrhea from other parts of the country: $1.4 \%$ from the north [16], 5.5\% from the east [17] and 5.6\% from the west [18]. Among the HIV-seropositive individuals, Cryptosporidium was found in $6.85 \%$ of cases. A similar prevalence was reported from other parts of the country: $10.8 \%$ in North India [19] and $8.5 \%$ in West India [20]. In South India, a high prevalence of $25.2 \%$ was reported from Vellore [11], but a relatively lower prevalence of $14 \%$ was reported from Chennai, which is located nearby [21]. Cyclosporiasis and isosporiasis are caused exclusively by human species. Most species of Cryptosporidium appear to have some host specificity, but they are not strictly host specific [25]. The development of molecular tools to identify morphologically indistinguishable genotypes / species has promoted our understanding of the epidemiology of the parasite. Five species of Cryptosporidium namely the human species $C$. hominis and zoonotic species $C$. parvum, $C$. meleagredis, $C$. felis, $C$. canis have been shown to be responsible for most human infections. Although cryptosporidiosis is prevalent in India, only three studies have characterized Cryptosporidium at the molecular level, two in pediatric $[10,22]$ and one in HIV-positive cases [11]. In our study, the two species $C$. hominis and $C$. parvum were detected. $C$. hominis was the most common in both pediatric $(69.2 \%)$ and HIV-positive patients $(75 \%)$, a finding comparable to the other studies in our country [10, 11, 22 ]. This suggests that anthroponotic transmission is predominant in this geographical area while zoonotic transmission occurs to a lesser extent. Other species like $C$. felis $C$. meleagredis and $C$. muris reported in the other studies were not detected in our study. However, mixed infection with $C$. hominis and $C$. parvum was seen in $12.8 \%$ of pediatric isolates, although not in HIV-infected cases. In contrast, mixed infections have been reported in HIV-infected persons from other countries [26]. The significance of mixed infection is not clear, because there was no significant difference in severity or duration of illness among children infected with mixed genotypes. However, it may reflect a common source of infection and the co-circulation of the two genotypes in the environment. Since the subtyping of $C$. parvum isolates has revealed the existence of anthroponotic and zoonotic variants [27], subtyping of $C$. parvum isolates from humans and animals is required to understand the transmission cycles of the parasite in this geographical area.

Among the HIV-seropositive patients, Isospora belli was the most common coccidian parasite $(16 \%)$. A similar finding has been reported by several authors [20, 21, 27]. In contrast, low prevalence $(2.5 \%)$ was reported in North India where Cryptosporidium was found to be most common coccidian parasite [19]. However, Isospora was infrequently reported from other developing countries like Peru (1.4\%) [28], Brazil ( $7 \%$ ) [29] and Thailand (4.5\%) [30]. Isospora was not detected in pediatric cases. There are no reports on isosporiasis in children in India except for a study from Delhi, where only 7 cases of isosporiasis were detected over a period of one decade, out of which two were HIV-infected [31]. These findings suggest that, although Isospora is prevalent in the environment, it has not yet evolved as an endemic pathogen and remains as an opportunistic pathogen only. This is in contrast to Cryptosporidium, which not only occurs frequently as an opportunistic pathogen but is also associated with endemic disease.

Among HIV-positive patients, Cyclospora was found at a very low frequency $(0.6 \%)$. Several other studies have reported a low prevalence rate of $0-1 \%$ [20, 21, 27]. In contrast, a study from Mumbai reported $6.6 \%$ prevalence among HIV-infected persons with diarrhea [32]. Higher prevalence rates have also been reported from Haiti (11\%) [33] and Venezuela (9.8\%) [6].

In the present study, Cyclospora was not detected among the pediatric population. There are no reports on pediatric cyclosporiasis in India, except for a case report in an infant [34], a fact that may reflect the low occurrence of the parasite in the environment. This is in contrast to the $5 \%$ prevalence reported among symptomatic children from $\mathrm{Ne}$ pal, a neighboring country [7]. A high prevalence rate was also reported among children in Peru (13\%) [5] and Venezuela $(5.3 \%)$ [6]. Some authors have reported a high prevalence of asymptomatic infection among children living in severe poverty and unhygienic conditions in developing countries [35, 36].

All of the three coccidian parasites have been reported infrequently among immunocompetent adults worldwide [1, $3,30,37]$. In our study, Cryptosporidium was found infrequently in immunocompetent adults $(1 \%)$, but much more frequently among children $(8.7 \%)$, indicating an acquired immunity to this parasite in the adult population. $C y$ clospora and Isospora were detected in neither children nor immunocompetent adults, suggesting their existence as opportunistic pathogens in this geographical area.

Our study has certain limitations. Since it is a hospitalbased study mild infections might not have been examined, and the examination of single fecal samples from each patient could have resulted in lower prevalence rates. Community-based longitudinal studies are required to assess the actual disease burden caused by these new parasites and to elucidate their epidemiology. 


\section{CONCLUSION}

In the present study, Isospora belli was found to be the most common emerging protozoan parasite among HIVinfected persons. Cryptosporidium was found to be prevalent among children and HIV-seropositive adults, indicating its endemicity in this region. Cyclospora appears to be an infrequent pathogen in this geographical area.

\section{ACKNOWLEDGEMENT}

This Study is supported by a grant from the Department of Biotechnology, Government of India, New Delhi (BT/PR/2716/MED). We thank C.S.Bhaskaran and Savitri Sharma for their assistance in the preparation of the manuscript.

\section{REFERENCES}

1 . Good game RW (1996) Understanding intestinal sporeforming protozoa: cryptosporidia, microsporidia, Isospora, and Cyclospora. Ann Intern Med. 124: 429-441

2 . Current WL, Garcia LS (1991) Cryptosporidiosis. Clin Microbiol Rev. 4: 325-358

3. Ooi WW, Zimmerman SK, Needham CA (1995) Cyclospora species as a gastrointestinal pathogen in immunocompetent hosts. J Clin Microbiol 33: 1267-1269

4 . Lindsay DS, Dubey JP, Blagburn BL (1997) Biology of Isospora spp. from humans, nonhuman primates, and domestic animals. Clin Microbiol Rev 10: 19-34

5 . Cordova Paz Soldan O, Vargas Vasquez F, Gonzalez Varas A, Perez Cordon G, Velasco Soto JR, Sanchez-Moreno M, Rodriguez Gonzalez I, Rosales Lombardo MJ (2006) Intestinal parasitism in Peruvian children and molecular characterization of Cryptosporidium species. Parasitol Res 98: 576-581.

6 . Chacin-Bonilla L, Estevez J, Monsalve F, Quijada L. (2001) Cyclospora cayetanensis infections among diarrheal patients from Venezuela. Am J Trop Med 65: 351-354

7 . Hoge CW, Echeverria P, Rajah R, Jacobs J, Malthouse S, Chapman E, Jimenez LM, Shlim DR (1995) Prevalence of Cyclospora species and other enteric pathogens among children less than 5 years of age in Nepal. J Clin Microbiol 33: 3058-3060

8 . Ortega YR, Sterling CR, Gilman RH, Cama VA, Diaz F (1993) Cyclospora species - a new protozoan pathogen of humans. N Engl J Med 328: 1308-1312

9 . Xiao L, Bern C, Limo J, Suleiman I, Roberts J, Checkley W, Cabrera L, Gilman RH, Lal AA (2001) Identification of 5 types of Cryptosporidium parasites in children in Lima, Peru. J Infect Dis 183: 492-497.

10. Das P, Roy SS, MitraDhar K, Dutta P, Bhattacharya MK, Sen A, Ganguly S, Bhattacharya SK, Lal AA, Xiao L (2006) Molecular Characterization of Cryptosporidium spp. from Children in Kolkata, India. J Clin Microbiol 44: 4246 -4249 .

11. Muthusamy D, Rao SS, Ramani S, Monica B, Banerjee I, Ooriapadickal CA, Dilip CM, Beryl P, Jayaprakash M, Christine AW, Honorine DW, Gagandeep K, (2006) Multilocus genotyping of Cryptosporidium sp. isolates from human immunodeficiency virus-infected individuals in South India. J Clin Microbiol 44: 632-634

12 . Pieniazek NJ., Bornay - Llinares FJ., Slemenda SB, Alexander da Silva J, Moura IN,.Arrowood MJ, Ditrich O, Addiss. (1999) New Cryptosporidium genotypes in HIV infected persons. Emerg infect Dis . 5: 444 -449

13. Morgan UR, Weber R, Xiao L, Sulaiman I, Thompson RC, Ndirutu W, Lal AA, Moore S, Deplazes P.( 2000) Molecular characterization oc Cryptosporidium isolates obtained from human immunodeficiency virus-infected individuals living in Switzerland, Kenya and the United States. J Clin Microbiol 38:1180-1183

14 . Thompson RCA, Olson ME, Zhu G, Enomoto S, Abrahamsen MS, Hijjavi NS. (2005) Cryptosporidium and cryptosporidiosis. Adv Parasitol 59: 77-158

15. Mathan MM, Venkatesan S, George R, Mathew M, Mathan VI (1985) Cryptosporidium and diarrhoea in southern Indian children. Lancet 23: 1172-1175

16. Sethi S, Sehgal R, Malla N, Mahajan RC (1999) Cryptosporidiosis in a tertiary care hospital. Natl Med J India 12: 207-209

17. Das P, Sengupta K, Dutta P, Bhattacharya MK, Pal SC, Bhattacharya SK (1993) Significance of Cryptosporidium as an etiological agent of acute diarrhoea in Calcutta, a hospital based study. J Trop Med hyg 96: 124 -127

18 . Saraswathi K, Pandit DV, .Deodhar LP, .Bichile LS, (1988) Prevalence of Cryptosporidia in patients with diarrhoea in Bombay. Indian J Med Res 87 : 221 -224

19. Mohandas, Sehgal R, Sud A, Malla N (2002) Prevalence of intestinal parasitic pathogens in HIV-seropositive individuals in Northern India. Jpn J Infect Dis $53: 83-84$

20 . Joshi, M, Chowdhary AS, Dalal PJ, Maniar JK (2002) Parasitic diarrhoea in patients with AIDS. Natl Med J India 15 : 72-74

21. Kumar SS, Ananthan S, Lakshmi P (2002) Intestinal parasitic infection in HIV infected patients with diarrhoea in Chennai Indian J Med Microbiol 20: 88-91

22. Ajjampur SS, Gladstone BP, Selvapandian D, Muliyil JP, Ward H, Kang G.(2007) Molecular and spatial epidemiology of cryptosporidiosis in children in a semiurban community in South India. J Clin Microbiol 45:915-920

23. Garcia LS, Bruckner DA, Brewer TC, Shimizu RY (1983), Techniques for the recovery and identification of Cryptosporidium oocysts from stool specimens. J Clin Microbiol 18: $185-190$

24. Xiao L, Escalante L, Yang C, Sulaiman I, Escalante AA, Montali R J, Fayer R, Lal AA (1999) Phylogenetic analysis of Cryptosporidium parasites based on the smallsubunit rRNA gene locus. Appl Environ Microbiol 65 : 1578-1583.

25. Fayer R.(2004) Cryptosporidium:a waterborne zoonotic 
parasite. Vet Parasitol126:37-56

26. Cama V, Gilman RH, Vivo A, Ticona E, Ortega Y, Bern C, Xiao L ( 2006) Mixed Cryptosporidium infections and HIV. Emerg Infect Dis 12 : 1025-1028

27 . Alves M, Xiao L, Sulaiman I, Lal AA, Mato O, Antunes F. (2003) Subgenotype analysis of Cryptosporidium isolates from human, cattle and zoo ruminants in Portugal. J Clin Microbiol. $41: 2744-2747$.

28. Carcamo C, Hooton T, Wener MH, Weiss N S, Gilman R, Arevalo J, Carrasco J, Seas C, Caballero M, Holmes KK (2005) Etiologies and manifestations of persistent diarrhea in adults with HIV-1 infection: a case-control study in Lima, Peru. J Infect Dis 191: 11-19

29. Silva CV, Ferriera MS, Borges AS, Costa-Cruz JM (2005) Intestinal parasitic infections in HIV/AIDS patients: experience at a teaching hospital in central Brazil. Scand J Infect Dis $37: 211-215$

30 . Waywa D, Kongkriengdaj S, Chaidatch S, Tiengrim S, Kowadisaiburana B, Chaikachonpat S, Suwanaqool S, Chaiprasert S, Curry A, Bailey W, Suputtamongkol Y, Beeching NJ (2001) Protozoan enteric infection in AIDS related diarrhoea in Thailand.Southeast Asian J Trop Med Public Health. 32 Suppl 2 : 151s-155s
31. Mirdha BR, Kabra SK, Samantray JC (2002) Isosporiasis in children. Indian Paediatr 39: 941-944

32 . Deodhar L, Maniar JK, Saple DG (2000) Cyclospora infection in immunodeficiency syndrome. J Assoc Physicians India $48: 404-406$

33 . Pape JW, Verdier EI, Boncy M, Boncy J, Johnson WD Jr (1994) Cyclospora infection in adults infected with HIV : clinical manifestations, treatment and prophylaxis. Annals Int Med 121: 654-657.

34 . Iyer RN (2006) Cyclosporiasis in an infant. Indian J Med Microbiol 24 : 144-145

35. Lopez AS, Bendik JM,. Alliance JY, Roberts JM, da Silva AJ, Moura IN, Arrowood MJ, Eberhard ML. (2003) Epidemiology of Cyclospora cayetanensis and Other Intestinal Parasites in a Community in Haiti. J Clin Microbiol 41: 2047-2054

36. Eberhard ML, Nace EK, Freeman AR, Streit TG, da Silva AJ, Lammie PJ.(1999) Cyclospora cayetanensis infections in Haiti: a common occurance in the absence of watery diarrhea. Am J Trop Med Hyg 60:584-586

37 . Wolfson JS, Richter JM, Waldron MA, Weber DJ, McCarthy DM, Hopkins CC (1985) Cryptosporidiosis in immunocompetent patients. N Engl J Med 312:1278-1282. 